Scotland earlier than was thought, and (c) the influence of Baltic Forest Culture was more widespread in Scotland, both in geographical distribution and duration in time than has generally been held to be the case.

So far, only the more complex Antrim raised beach provides evidence of the evolution of the lithic element in the pre-Neolithic culture which flourished on the shores of south-western Scotland and northeastern Ireland, but there exist indications to suggest that future inquiries in Scotland will afford analogies.
The Campbeltown Early Mesolithic industry must antedate the advanced bone and antler industries from the Argyll shell-mounds and caves, the situation of which points to occupation during Late Atlantic times following the maximum submergence. This is possibly equatable with the Littorina transgression of the Baltic. In Baltic chronology, which cannot yet be applied with certainty to Scotland, the period of the Littorina raised beach may be taken as 5000-2500 B.c., the maximum transgression in Denmark taking place about 4500 B.c.

\title{
EARLY MATERIA MEDICA CABINETS
}

A $S$ a quiet and pleasing relief from topics bearing A upon the War, Mr. E. Saville Peck took as the subject of his lecture at the February scientific meeting of the Pharmaceutical Society "Three Early Materia Medica Cabinets in Cambridge".

The collections described, namely, those of J. P. Vigani, John Addenbrooke and William Heberden are of special interest for various reasons, but notably because they mark the time when the atmosphere of indifference to medical teaching which had hitherto prevailed at Cambridge began to be dispelled. Vigani, a native of Verona, who had taught chemistry in Cambridge for twenty years, was invested with the title of professor of chemistry in 1703, and it would seem that a chest containing more than six hundred specimens of materia medica, which was found in 1922 under the staircase of the library of Queens' College, was the one from which he lectured.

Mr. Peck has told, on a previous occasion, of the evidence on which he based his belief, and his description of the contents of the chest, which was published some years ago, forms a useful addition to the literature of drugs.

John Addenbrooke's chest, now in St. Catherine's Library, contains, besides the drugs, many geological specimens which he collected and labelled when in his undergraduate days he used "to range the circumjacent country, Cherryhinton, Grantchester and Trumpington and searched the chalk pits and moors for fossils and simples". The chest itself is made of deal and is much the same in shape as a flat-topped writing desk of the present day, having a frog hole in the middle, drawers all the way down and also at the back of the recess; each drawer is divided by wooden partitions into compartments of about 3 inches square. There are about twenty such drawers containing a fine collection of materia medica. Perhaps the best of these collections are the drawers containing gums, resins and the like, the drawer of roots and rhizomes and another containing barks and woods, and still another filled with seeds. Some of these specimens were labelled by Addenbrooke himself.

Incidentally, there is a fine specimen of coffee berries in Addenbrooke's chest; this "drug" had but recently been introduced, and a few years earlier, in 1680, had been described as being "most useless, since it serves neither for nourishment nor debauchery". Among other drugs introduced in the seventeenth century and specimens of which Addenbrooke collected, were jalap, serpentaria, calumba and balsam of Tolu.

The third chest described by Mr. Peck was that of William Heberden, who was admitted a sizar of St. John's in 1724, and was made a medical fellow in 1734, proceeding to the degree of M.D. in 1739 . $\mathrm{He}$ gave an annual course of lectures in materia medica, and made good use of his knowledge of the classics to adorn them; the collection of materia medica which he had formed to illustrate his lectures he presented to his college when he left Cambridge to practise in London, where among his patients was Dr. Johnson. Boswell relates that when he was asked what physician he had sent for, he replied, "Dr. Heberden, ultimum Romanorum".

Heberden's cabinet is made of oak and contains in the upper portion twenty-eight drawers and below a cupboard with two shelves. The contents are noted in a manuscript catalogue of July 10, 1751. The three cabinets described have many points of similarity; all three contain almost identical substances, most of which are mentioned in Culpeper's Herbal and the London Pharmacopœia of the time. They are contained in little paper trays folded in similar fashion and placed in the various positions in the drawers.

Cambridge is fortunate in possessing such treasures and, as Mr. Peck acknowledged, pharmacists are grateful to the Colleges for the care they have taken of them for more than two centuries.

\section{RECOGNITION OF COLOURED LIGHT SIGNALS}

$\mathrm{A}$ PAPER was read to the Illuminating Engineering Society on February 11 by J. G. Holmes on the recognition of coloured light signals. The apparatus described in the first part of the paper was made to provide a spot of coloured light suitable for observation under conditions comparable with night signalling, and capable of variation through a wide range of colours, the energy distributions of which were similar to those of the usual signalling colours.

The apparatus is similar to the Donaldson colorimeter, but with eleven primaries. Eleven beams of light from a common light source pass through coloured filters and through adjustable apertures, 
before being mixed in an integrator, and any required colour is obtained by combining the appropriate amounts of the three nearest primary beams. The range of colours covers the spectrum from extreme red to emerald green $(550 \mathrm{~mm}$.) and the area enclosed by this spectrum, and turquoise, royal blue, and purple with provision for particular consideration of white and yellow. The calibration was done with great care with a view of eliminating relative error between similar colours and to allow of statistical examination of results.

The test colours were obtained by the use of stencils selecting the primary beams, which gave 256 points on the colour chart, all being of the same luminous intensity and brightness, and each having a closely similar energy distribution to that which would be given by the corresponding colour filter, and would be used in practice.

The method of experiment was to show the 256 colours in random succession to an observer who was asked to give one of the simple names, red, yellow, green, blue, purple or white - to each test colour. This experiment was repeated for fifty observers, all of normal colour vision, and thus the number of times that any particular colour was given a particular name was found. Contours were then drawn on the colour chart showing the percentage frequency with which those simple names occurred over the whole area covered by the apparatus. A diagram is given showing the distribution of the names 'red' and 'green' for an illumination of 10 sea-mile candles at the observer. The experiment was further repeated with six observers selected to give average results, each making three observations at four different illumination levels, and with several different choices of names such as red, green, or white, and red, yellow, green or white and so on, and contours were drawn for each set of conditions. Experiments were carried out on the effect of a comparison light, light adaptation, and presbyopic vision, and altogether some 43,000 observations have been analysed and are represented in the diagrams.

The results are difficult to summarize, as the experiments were intended as a contribution to knowledge of colour recognition rather than a complete statement of the distribution of colour names. Red is the ideal signalling colour, being easily produced and yet recognized down to the lowest illuminations, even when not fully saturated. Green is satisfactory under usual conditions, but must be considerably restricted if blue is also used for signalling. Blue and purple cannot be regarded as satisfactory, the former requiring very high intensity and the latter depending on the dichromatic aberrations in the eye. Yellow and white are satisfactory if used separately, but they cannot be used together unless the white approximates to daylight.

It may be noted that whereas yellow has often been thought unsatisfactory, because of the confusion with white, the case is really that many whites are unsatisfactory because they are themselves too yellow. No significant difference was found between monochromatic sodium light and the equivalent lamp and filter combination. Presbyopic vision and light adaptation both assisted the recognition of blue and purple signals.

The paper concludes with a calculation of the optimum transmission factor for green colour filters based on the results obtained, and gives results which are reasonably consistent with those adopted in practice.

\section{FORTHCOMING EVENTS}

(Meeting marked with an asterisk is open to the public.)

\author{
Monday, April 7
}

Royal Geographical Society (at Kensington Gore, London, S.W.7), at 5 p.m.-Mr. W. E. Doran: "The Ouse Drainage Problem".

\section{Tuesday, April 8}

Chadwick Public Lecrure (at the London School of Hygiene and Tropical Medicine, Keppel Street, London, W.C.1), at 2.30 p.m.- "Air Raid Shelters-Design and Construction, with special reference to Hygienic Con. siderations" (Dr. S. L. Wright: "Hygienic Considerations"; Mr. Phillip O. Reece : "Design and Construction").*

Illominating EngINeERING Society (at the E.L.M.A. Lighting Service Bureau, 2 Savoy Hill, London, W.C.2), at 2.30 p.m.-Dr. J. W. T. Walsh : "The Measurement or Gauging of Low Values of Illumination and Bright. ness"; Mr. J. S. Dow: "Visibility by White and Coloured Light".

\section{Wednesday, April 9}

Sochety of Chemical Industry (at British Medical Association House, Tavistock Square, London, W.C.1), at 11 a.m.-Discussion on "Vegetables as Food".

\section{APPOINTMENTS VACANT}

APPLICATroNs are invited for the following appointments on or before the dates mentioned:

Woman Graduate In Physics-The Clerk to the Governors, South-East Essex Technical College, Longbridge Road, Dagenham (April 9).

PrINCIPAL OF THE Chiswick POLYTEChNic-The Secretary (T), Middlesex Education Committee, Acton County School, Gunnersbury Lane, London, W.3 (April 16).

Principal of the ENFIELd ThohNICAL Collegk-The Secretary (T), Middlesex Education Committee, Acton County School, Gunnersbury Lane, London, W.3 (April 16).

Principal of THE TOTTENHAM TECHNICAL COLLEGE-The Secretary (T), Middlesex Education Committee, Acton County School, Gunnersbury Lane, London, W.3 (April 16).

Principal of LURGAN TECHNICAL INSTrTUTE-Mr. H. O. Armstrong, Technical Institute, Lurgan, Co. Armagh (April 21).

TEACHER (MAN) OF ENGINEERING AND MATHEMATICS at the Grimsby Technical College- The Director of Education, Education Offices, Eleanor Street, Grimsby (April 30).

Teacher of Mining and Engineering SubJects-The Principal, Technical Institute, Canterbury.

Professor of PAThology and a Professor of PHysiology-The Secretary, University College, Cork.

ENGINEER for the Public Works Department of the Government of Sierra Leone-The Crown Agents for the Colonies, 4 Millbank, London, S.W.1 (quoting M/9552).

\section{REPORTS AND OTHER PUBLICATIONS}

\author{
(not included in the monthly Books Supplement)
}

\section{Great Britain and Ireland}

British Electrical and Allied Industries Research Association. Technical Report,. Reference W/T4: Improvement of Load Factor in Farm Grinding. By W. H. Cashmore and C. A. Cameron Brown. Pp. 30. (London: British Electrical and Allied Industries Research
A 63

Philosophical Transactions of the Royal Society of London. Series A : Mathematical and Physical Sciences. No. 802, Vol. $239: \mathbf{X}-\mathbf{R} a y$ Crystallography and the Chemistry of the Steroids, Part 1. By J. D. Bernal, Dorothy Crowfoot and I. Fankuchen. Pp. 135-182. 78. 6d. Series B : Biological Sciences. No. 574, Vol. 230: The Colours of the Plumose anemone Metridium senile (L.). By D. L. Fox and C. L. A. Pantin. Pp. 415-450. 5s. 6d. No. 575, vol. 230: On the Bicoecida, a Family of Colourless Flagellates. By L. E. R. Picken. Pp. 451-474,

Proceedings of the Royal Society of Edinburgh. Section A (Mathematical and Physical Sciences.) Vol. 61, Part 1, No. 1: On Hamilton's Principal Function in Quantum Mechanics. By E. T. Whittaker. Principal Function in Quantum 19. 18.7d. Vol. 61, Part 1, No. 2: The Van der Walls Force between a Proton and a Hydrogen Atom. By Dr. C. A. Coulson. Pp. 20-25. 6d. Vol. 61, Part 1, No. 3 : Reciprocity, Part 5: Reciprocal Spinor Functions. By Dr. Klaus Fuchs. Pp. 26-36.
(Edinburgh and London: Oliver and Boyd.) 